\section{La larga marcha hacia la regulación de calidad en publicidad oficial en México}

AUTORES / AUTHORS

Jacqueline Peschard (coord.)

EDITORIAL / PUBLISHING COMPANY

México, UNAM, 2019, 120 pp.

http://www.libros.unam.mx/la-larga-marcha-hacia-la-regulacion-de-calidad-en-publicidad-oficial-enmexico-9786073015486-libro.html
- Recibido / Received 6 de octubre de 2020

- Aceptado / Acepted 16 de octubre de 2020

- Páginas / Pages De la 365 a la 368

- ISSN: $1885-365 \mathrm{X}$

La relación entre medios de comunicación y el Estado no es nueva. Se ha registrado, desde tiempo atrás, que dicho vínculo, necesario para transmitir a la población ha derivado en discrecionalidad, discriminación y cooptación. Por ello, es necesario regular los recursos públicos destinados a la publicidad oficial. De esto trata el libro La larga marcha hacia la regulación de calidad en publicidad oficial en México, coordinado por una voz acreditada, Jacqueline Peschard, titular del Seminario Universitario de Transparencia de la Universidad Nacional Autónoma de México.

Cuatro secciones integran esta publicación: I. La regulación de publicidad oficial en perspectiva comparada; II. La evolución de la normatividad en México; III. El funcionamiento de la publicidad oficial: instituciones y medios, y IV. Prospectiva en el contexto del nuevo gobierno.

La primera sección abre con el trabajo de Gustavo Gómez, titulado «Aspectos claves para una regulación sobre publicidad oficial compatible con la libertad de expresión», en donde aborda el concepto de "censura indirecta», entendido como aquella acción estatal que impacta en la libertad de expresión, utilizando recursos públicos para asignar publicidad oficial. Al respecto, retoma los documentos «Violaciones indirectas de la libertad de expresión: Asignación discriminatoria de la publicidad oficial» $y$ «Principios sobre regulación de la publicidad oficial en el Sistema Interamericano de Protección de los Derechos Humanos», elaborados por la Relatoría Especial para la Libertad de Expresión de la Comisión Interamericana de Derechos Humanos de 2003 y 2011, respectivamente, en donde se señala que existen formas de censura, ocultas detrás de un velo de legitimidad, que limitan la libertad de expresión al condicionar la publicidad estatal a los medios de comunicación. En este capítulo, el autor propone una serie de elementos que deben contener las leyes sobre el pautado oficial: no utilizar recursos públicos para premiar o castigar a medios o comunicadores; el uso de la publicidad oficial se debe regular mediante una ley específica que delimite sus objetivos y definición; las leyes en esta materia deben incorporar los principios de transparencia, rendición de cuentas, objetividad, no discriminación, eficiencia y austeridad; debe incluir a qué se refiere la expresión publicidad oficial; la asignación de este tipo de publicidad debe hacerse por concursos; los criterios para la asignación de publicidad deben ser objetivos y profesionales; este tipo de publici- 
dad no puede ser considerada como una forma de subsidio a determinados tipos de medios; la transparencia es un elemento fundamental al momento de diseñar una regulación compatible con los derechos humanos; deben adoptarse medidas para implementar el control independiente y externo de la publicidad oficial, mediante órganos independientes, y sin información suficiente y de calidad, la distribución de la publicidad oficial no podrá seguir criterios técnicos.

El segundo capítulo, «Apuntes sobre regulación comparada y publicidad oficial», es de Aleida Calleja, y en él se explica que la publicidad oficial no debe servir para mantener vivos a medios de comunicación - públicos o privados - , ya que su función principal es informar sobre cuestiones de interés colectivo y servir como instrumento de transparencia y rendición de cuentas. Por otro lado, se destaca que los subsidios oficiales a los medios de comunicación no son un derecho de éstos pero sí incentivan la pluralidad y fortalecen el debate público. No debe existir una intromisión del poder público - a través de la publicidad - en las líneas de los medios y, por ello, el pautado debe considerar la planificación anual de las campañas publicitarias, el público objetivo, los precios de adquisición y la circulación para medios gráficos o audiencia (televisión, radio e Internet). Asimismo, es recomendable que los recursos para este objetivo no estén centralizados en una oficina de naturaleza política, sino que deberían encontrarse en un organismo técnico que decida con base en criterios sujetos de medición en términos de impacto de los mensajes. La autora examina la legislación al respecto de Canadá, Argentina, Bélgica, Francia, Holanda y Portugal.

«La discusión pública de la publicidad oficial y el impulso de la sociedad civil: una perspectiva desde América Latina», de Grisel Salazar y Octavio Olea, es el capítulo de esta primera sección en donde los autores ofrecen una revisión de las regulaciones en materia de publicidad oficial en los países latinoamericanos donde éstas existen, enfocándose en los elementos que incluye la ley y en las obligaciones de transparencia; es decir, en qué información sobre publicidad oficial debe difundirse.

En 2018, cinco países latinoamericanos tenían leyes sobre publicidad oficial: Argentina, Colombia, Perú, Uruguay y México. En Chile, Ecuador y Paraguay existe alguna ley afín que regula algún ámbito de la publicidad oficial. Los elementos fundamentales de estas normas son los sujetos obligados (en Argentina, Colombia y Perú es el Poder Ejecutivo, y en México y Uruguay todos los poderes y órganos estatales); las leyes mexicana y uruguaya señalan principios transversales que rigen la aplicación de la norma: transparencia, máxima publicidad, imparcialidad y eficiencia. Exceptuando la legislación mexicana, en Argentina, Colombia, Perú y Uruguay existen dos criterios para distribuir la publicidad: en función del alcance o cobertura del medio de comunicación (Argentina, Perú y Uruguay), y de la población objetivo de la campaña de publicidad (Colombia, Perú y Uruguay). Los autores concluyen señalando que hay divergencias importantes en las legislaciones: carencia de una definición uniforme de los principios que el gasto en publicidad oficial debe atender, de los criterios de distribución, o sobre el padrón de medio; y coinciden en cuanto los sujetos obligados, la necesidad de tener un plan de comunicación y la exigencia de transparentar lo concerniente a los contratos publicitarios.

La segunda sección, destinada al examen de la circunstancia mexicana, se inicia con el trabajo de Justine Dupuy, Paulina Castaño, Ana Cristina Ruelas y Ricardo Reyes, «Publicidad oficial y libertad de expresión. De la sentencia de la SCJN a la Ley General de Comunicación Social». En él, se analiza el amparo concedido por la Suprema Corte de Justicia de la Nación (SCJM) a la organización Artículo 19 en donde se reconoció que la omisión legislativa de no 
regular la publicidad oficial violaba derechos fundamentales y obligaba al poder Legislativo a emitir la ley reglamentaria sobre publicidad oficial. La relevancia de la sentencia otorgada por el máximo tribunal puede sintetizarse en cuatro puntos:

- La SCJN obligó al Poder Legislativo a cumplir con lo dispuesto en la Constitución: «el Poder Legislativo no es libre para decidir no legislar»;

- La resolución amplía las posibilidades del juicio de amparo;

- Se abrió la posibilidad de tener en unos meses una Ley Reglamentaria que regule la publicidad oficial;

- Se expresa que el Estado debe ser neutral al asignar recursos a los medios. El capítulo reseña el proceso de las consultas entre ciudadanos y legisladores, el activismo de organizaciones de la sociedad civil y los desencuentros entre políticos y ciudadanos.

José Mario de la Garza Marroquín, en nombre de Barra Mexicana Colegio de Abogados, escribió «Transparentar el gasto público en la contratación de propaganda gubernamental», en donde propone lineamientos para la contratación de la propaganda gubernamental:

- Procurar un criterio de pluralidad, equidad y eficiencia en la distribución del presupuesto destinado a contratación de publicidad oficial en medios de comunicación;

- Indicar criterios sobre la forma que distribuyen la publicidad conforme con la planificación anual y con sus objetivos estratégicos;

- Definir los costos globales, las tarifas unitarias y los resultados esperados por cada campaña informativa de cada medio respecto del servicio solicitado;

- Publicitar los procesos de elección de proveedores para cada acción de comunicación que realicen;

- Establecer un programa operativo anual;

- Publicar el listado pormenorizado de los convenios de publicidad celebrados con cada medio.

La sección III «El funcionamiento de la publicidad oficial: instituciones y medios», abre con el trabajo de Jacqueline Peschard, Grisel Salazar y Octavio Olea, «La publicidad oficial en México: un problema de transparencia "opaca"», donde exponen las deficiencias en materia de transparencia y acceso a la información vinculadas a la publicidad oficial, haciendo énfasis en los elementos de opacidad existentes en los criterios de asignación de recursos, la definición de los rubros de gasto, y los de los medios y proveedores de servicios relacionados. Examinan las normas existentes en México en materia de acceso a la información sobre publicidad oficial, proponen «el mapa de la oscuridad», conceptualizado como un inventario de aspectos sobre publicidad oficial importantes: criterios de asignación del gasto, los resultados de las campañas publicitarias y los datos sobre medios y audiencias. Asimismo, se ofrece el panorama de la «transparencia opaca»; es decir, es la exploración de los temas que sí son susceptibles de conocerse por medio de la plataforma Comunicación Social o de los portales de entidades públicas, pero que suponen problemas de transparencia (información excesiva y poco manejable, y la divulgación parcial, confusa o fragmentada de información que dificulta comparar y homologar).

Raúl Trejo firma el capítulo «Acabar con la publicidad oficial» cuya tesis es eliminar el contubernio entre medios y poder público, el mismo que ha generado un periodismo que 
prefiera las facturas a los lectores. Instituciones públicas de todos los niveles (y sus titulares) promocionan sus logros. La autopromoción, dice el autor, está ligada a la manipulación, en el sentido que la publicidad oficial «moldea» la línea editorial. Algunos funcionarios, dueños de medios y periodistas hacen acuerdos en donde los que pierden son los ciudadanos. Para cambiar esto, es preciso que se extinga el subsidio publicitario oficial y su propuesta está integrada por un decálogo:

1. Que en el presupuesto público se prohíba la posibilidad de contratar espacios en los medios.

2. Esa medida se aplicaría dos años después de aprobada la nueva legislación en esta materia.

3. Durante los dos años de transición, el ejercicio del monto antes mencionado estaría destinado exclusivamente a la contratación de espacios en medios impresos o en línea.

4. Se crearía un Fondo para Auspiciar el Periodismo de Calidad y Socialmente Necesario con un porcentaje fijo del presupuesto federal que de ninguna manera sería superior al 0,05\% (en 2018 ese monto equivalió a 2.640 millones de pesos).

5. Los recursos de ese Fondo serían asignados, a partir de convocatoria abierta, por una comisión ciudadana, a publicaciones y proyectos caracterizados por su calidad, por la investigación periodística que realicen o por la especialización de sus contenidos.

6. Todos los medios podrán competir por la asignación de estos.

7. Los recursos del Fondo serían otorgados por un periodo de dos años no renovable para el bienio siguiente y nunca serían superiores al $50 \%$ de la financiación que la publicación beneficiada requiera para sostenerse.

8. El ejercicio de esos recursos no necesitaría de la inserción de publicidad ni condicionaría la política editorial del proyecto de comunicación que recibiera la financiación;

9. Para la difusión de los mensajes que tenga que comunicar a la sociedad, el Estado y sus instituciones dispondrán de los medios de carácter público, así como de los espacios en línea con los que ya cuenta y los que pueda habilitar.

10. Para promover el periodismo de calidad y su difusión sería asignar, mediante concurso abierto, los noticieros del Sistema Público de Radiodifusión del Estado Mexicano, el Canal 11 y las estaciones del Instituto Mexicano de la Radio, entre otros medios públicos.

Finalmente, la coordinadora de la obra, Jacqueline Peschard, cierra el libro con su capítulo «Prospectiva en el contexto del nuevo gobierno", que es un examen sobre lo anunciado por el gobierno federal entrante y las ventanas de oportunidad que los tomadores de decisiones tienen, considerando los estudios que desde la sociedad civil se han realizado y la experiencia que ésta misma tiene.

El libro es un insumo de muy alto valor para los tomadores de decisiones públicas, la academia y la sociedad, ya que sus reflexiones y propuestas están elaboradas con evidencia y buscan un nuevo equilibrio mediático que robustezca la democracia y genere una ciudadanía de alta intensidad.

\section{Por Dr. Eduardo Torres Alonso}

Universidad Nacional Autónoma de México (UNAM) 